\title{
Tourism Economy and Local Development in San-Pedro
}

\author{
Bolou Gbitry Abel \\ Jean Lorougnon Guédé-Daloa University, Ivory Coast \\ E-mail: gbitry2007@yahoo.fr \\ Gouaméné Didier-Charles \\ Jean Lorougnon Guédé-Daloa University, Ivory Coast \\ E-mail: gouam_didier@yahoo.fr \\ Boua Djaman Jean Didier \\ Jean Lorougnon Guédé-Daloa University, Ivory Coast \\ E-mail: jeandidierboua@gmail.com
}

Nassa Dabié Axel Désiré

Félix Houphouet-Boigny-Cocody University, Ivoiry Coast

E-mail: dabienassa@gmail.com

Received: March 4, $2021 \quad$ Accepted: May 2, $2021 \quad$ Published: May 4, 2021

doi: 10.5296/jsss.v8i1.18594 URL: https://doi.org/10.5296/jsss.v8i1.18594

\begin{abstract}
Coastal city of the Ivory Coast, San-Pedro is rich in natural, economic and tourist resources. This study analyses the contribution of the tourism economy to local development. Documentary research and a field survey were used to collect data. It should be remembered that San-Pedro has floristic, climatic and hydrographic assets. Moreover, human capital is one of the pillars of this activity with a diversity of actors, a socio-cultural wealth including remarkable historic sites (10) and twenty-eight (28) tourist establishments of varied standing.
\end{abstract}


Despite these assets, the tourist economy suffers from an organizational dysfunction and a weakness in investments. With $64 \%$ of the Ivorian workforce working mainly in informal or ephemeral sectors linked to the tourism economy, only $10 \%$ of the households surveyed said they were feeling the effects of it. The spatial, social and economic impact of the tourist sector remains below the real potential of this locality and below expectations.

Keywords: Contribution, Local development, Tourism economy, Pillars, San-Pédro

\section{Introduction}

The tourism economy has taken on a global dimension to such an extent that it has become the primary economic source for most developed and developing countries (Merlin and Choay, 2015). Thus, internationally, tourism contributed in 2013 to $9 \%$ of global GDP and created one in ten jobs. Also, the number of tourists has increased from 25 million in 1950 to 1078 million in 2013, reaching 1.1 billion visitors worldwide in 2014 (Perrain, 2018). Given this evolution of the sector, no one can ignore the role that tourism plays in a country's economy (N'Goran, 2009). For African countries, this activity represents an opportunity to promote economic growth and improve the living conditions of the population (Ashley, 2011). In this respect, since the colonial period for a country such as Morocco, the tourist activity is perceived as a promoter of development (Bencheikh et alii, 1999)

Côte d'Ivoire, a developing country, shows a growing interest in this sector of activity through the affirmation of the five-year plan of 1970 (Dégui et alii, 2019). This was done through the installation of an institutional framework for the development of tourism with the creation of a Ministry of State in charge of tourism and three tourism companies placed under the supervision of the said Ministry, namely SIETHO, ICTA, SIETHO in 1988 and 1990. Since then, the development of Ivorian tourism potential has been focused on two major orientations, namely the promotion of seaside tourism in the South of Côte d'Ivoire and the enhancement of discovery tourism for inland cities (Koffi, 2019). San-Pedro is an integral part of this project if we refer to the region's planning program. In 1998, this locality alone accounted for more than half of the largest hotels, which made it more attractive in the region. However, the global economic crisis of the 1980 s caused a drop in tourist flows to this locality. This situation worsened with the succession of the military-political crises of 1999, 2002, the post-electoral crisis of 2011 and COVID-19. These various crises have indeed ruined the hopes of investors and local populations heavily invested in this sector of activity (Gagui, 2011). This study is intended as a contribution of the participatory analysis of the tourism economy to local development in San-Pédro. Indeed, it was urgent to give all its importance to this issue because of the end of the various crises experienced by Côte d'Ivoire, particularly that of 2011. The Figure 1 below shows the study area. 


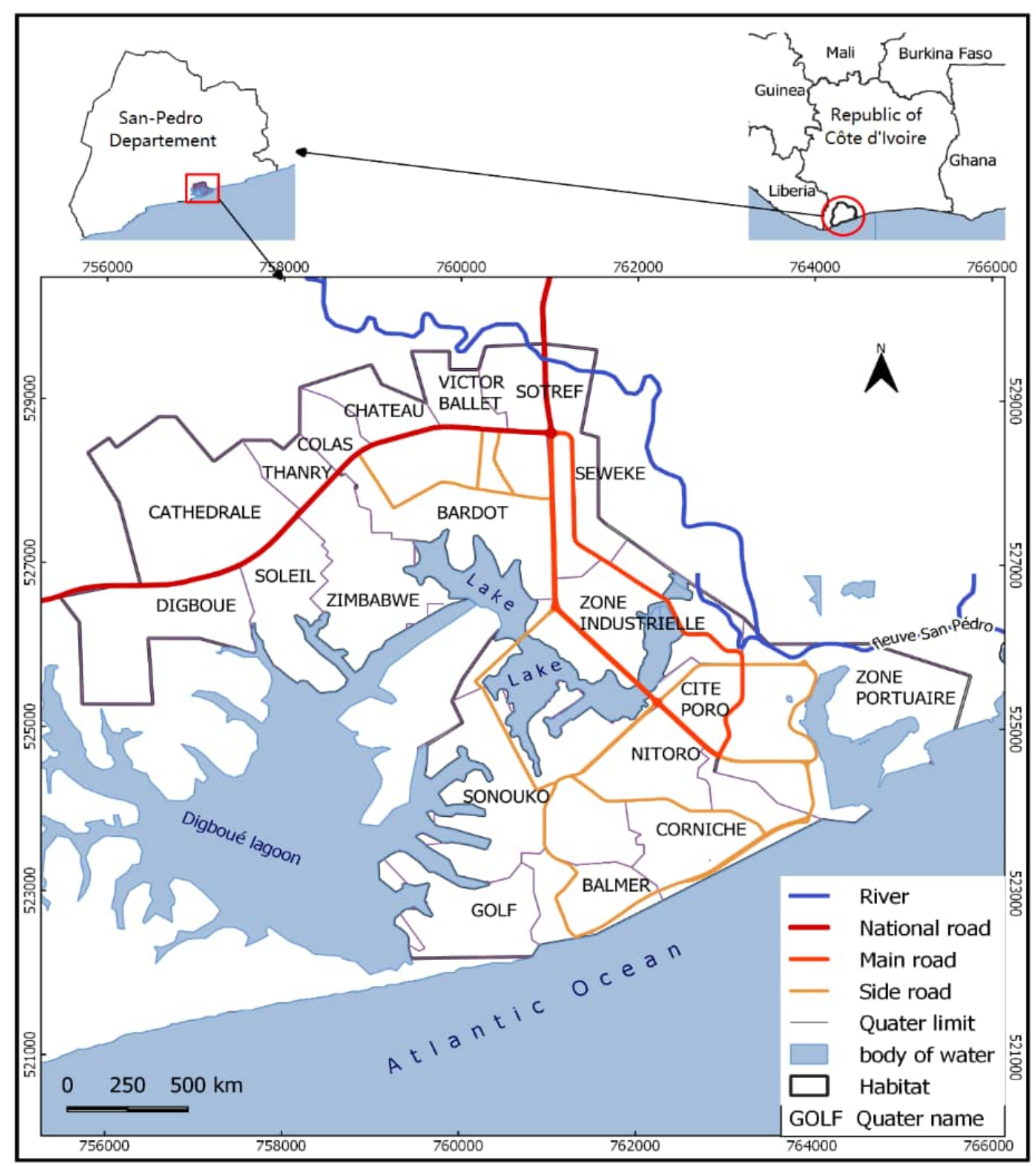

Figure 1. Presentation of the study area

Source: Town Hall, 2019; SOGEFI, 2019 Realization: the authors, 2020

\section{Data Collection Methods and Materials}

This study is based on two data collection techniques, namely documentary research and the field survey. The method adopted to conduct this research emanates from secondary and primary sources. The secondary source consists of works retracing the economy of Ivorian tourism. The consultation of these works was possible through search engines and university libraries. These include the library of the University Jean Lorougnon Guédé of Daloa (UJLoG), the Institute of Tropical Geography (IGT), the Institute of Research for 
Development (IRD) of Abidjan, etc. These have enabled the exploration of theses, dissertations, scientific articles and reports on tourism policies. However, apprehending the economics of tourism in the development of the city of San-Pedro could not be possible through this method. To do this, the field surveys consisted of the census of tourist establishments within the city of San-Pedro, interviews with public and private authorities were carried out. The selection of the sample of the population surveyed in this study was made by the probabilistic method for the household survey and not probabilistic for the other targets. For the collection of field data by questionnaire, three (3) population profiles were surveyed. These were tourists, economic operators in the tourism sector and households. The selection of the sample of the population surveyed in this study was made by the probabilistic method for the household survey and non-probabilistic for the other targets. As regards the probabilistic method, the target population is the number of households that make up the six (6) neighbourhoods that are representative of the different variants of the dynamism of the tourist activity found in the different neighbourhood profiles. This population is estimated at 5326 households, according to data from the 2014 General Population and Housing Census (RPGH-14). Thus, the accessible population is considered to be all the individuals likely to be affected by the study. This population is determined by the following formula:

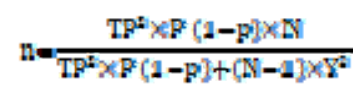

$\mathrm{n}=$ Sample size

$\mathrm{N}=$ Size of target population (total number of households)

$\mathrm{P}=$ Expected proportion of a response from the survey population. If no proportion value is available beforehand, it can be set to 0.5 by default.

$\mathrm{TP}=$ Confidence interval expressed at 95\%, 1.96

$\mathrm{Y}=$ The margin of sampling error with $\mathrm{Y}=0.05$

\section{Numerical application}

$$
\begin{aligned}
& \mathrm{n}=\frac{(1.96)^{2} \times 0.5 \times(1-0,5) \times 5326}{(1.96)^{2} \times 0.5 \times(1-0,5)+(5326-1) \times(0,05)^{2}} \\
& \mathrm{n}=346
\end{aligned}
$$

This means that 346 households were surveyed using the probabilistic method. In addition, in the absence of a consensual database on tourists, it seemed appropriate to use the reasoned choice method (non-probabilistic method) to determine the samples of tourists and operators to be surveyed. Indeed, the economic operators surveyed are essentially the managers of tourist sites. With reference to the operating licence issued by the Ministry of Tourism, the typology of tourist activity sectors and the active tourist sites, 28 economic operators were surveyed in the 28 identified tourist sites. The 60 tourists were also surveyed in these 28 sites using the accidental method.

In summary, 346 households, 28 economic operators and 60 tourists were surveyed, while 14 resource persons were interviewed (Table 1). 
Table 1. Distribution of the surveyed population by questionnaires in 2019 and 2020

\begin{tabular}{lll}
\hline surveyed persons & Type of survey & Surveyed persons numbers \\
\hline The tourists & Questionnaire & 60 \\
Business people & Questionnaire & 28 \\
households & Questionnaire & 346 \\
Reliable persons & Interview & 14 \\
Total & & $\mathbf{4 4 8}$ \\
\hline
\end{tabular}

Source: Field survey, January 2020.

The processing and analysis of the collected information was done using software through the computer. The word processing was done with Word software. The tables were produced with Excel software. For the cartographic representation of our results, Adobe Illustrator and Qgis software were used. The use of a Garmin 62 Global Positioning System (GPS) was helpful in recording geographic coordinates, and the use of a digital camera allowed photographs to be taken to illustrate the study.

\section{Results}

\subsection{A Plural Foundation of the Tourism Economy in San-Pedro}

The development of the tourism economy requires a number of advantages first. In San-Pedro, natural and human resources are the main determinants of the development of the tourism economy.

\subsubsection{Natural Resources as a Tourist Raw Material}

The natural potentials that contribute to the development of the tourism economy in San-Pedro are the hydrographic wealth, the fauna and flora resources as well as the climate. These assets are successively presented.

3.1.1.1 Hydrographic Wealth Favoring the Establishment of Tourist Establishments in San-Pedro

Three main rivers water the department of San-Pedro. It is the $150 \mathrm{~km}$ long San Pedro River, originating in the Taï National Park and flowing into the classified forest of the Grah Rapids. There is also the Nero River, $180 \mathrm{~km}$ long and covering an area of $900 \mathrm{~km}^{2}$. It waters the sub-prefecture of Grand-Béréby and takes its source in the department of Tabou. Finally, there is the presence of the Atlantic Ocean with an area of $12,790 \mathrm{~km}^{2}$. This water resource favors the establishment of tourist establishments in the city of San-Pedro (Figure 2). 


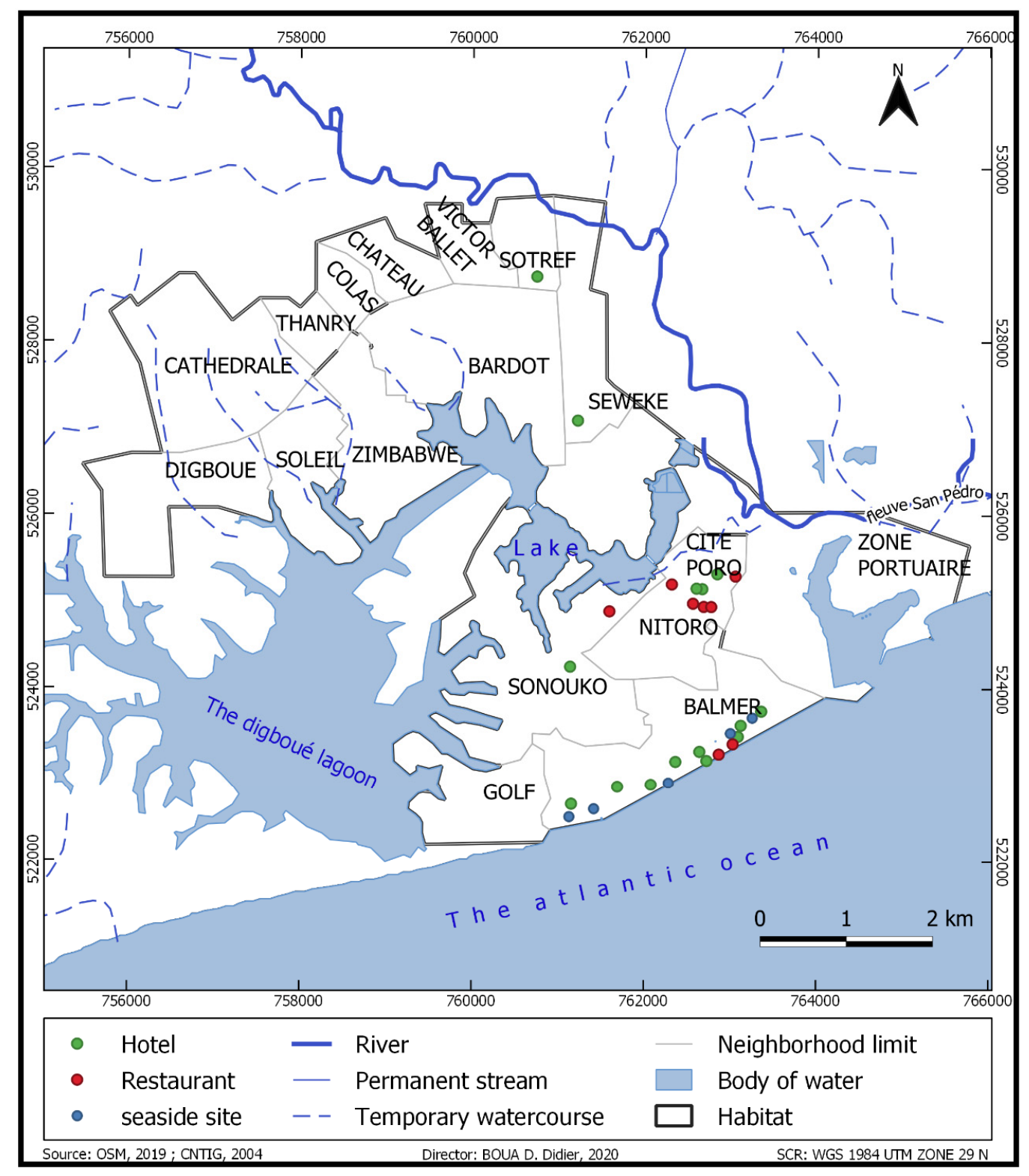

Figure 2. Location of tourist establishments in relation to the hydrographic network of the city of San-Pedro in 2020

Source: Town hall, 2019; SOGEFI, $2019 \quad$ Realization: the authors, 2020

The Figure above shows the location of tourist establishments in relation to the hydrographic network of the city of San-Pedro. The observation is that more than $71 \%$ of the surveyed tourist establishments are installed in the surroundings of these rivers, in particular the Atlantic Ocean in the Balmer district where we identify fifteen (15) establishments and around the San-Pedro river where five (5) establishments were identified. Thus, the rivers are of paramount importance for the development of the tourism economy in San-Pedro. This statement is supported by $90 \%$ of the economic operators of tourist establishments. For them, the freshness and the wind that these resources provide are appreciated by tourists. 


\section{Macrothink}

3.1.1.2 Attractive Fauna and Flora Resources Throughout the Department

The department of San-San-Pedro is full of several species of fauna and flora, 7 and 11 of which are respectively of tourist interest. They are animals of the forest and the aquatic environment (Regional Directorate of Water and Forests, 2020). An illustration of these species is made (Figure 3).

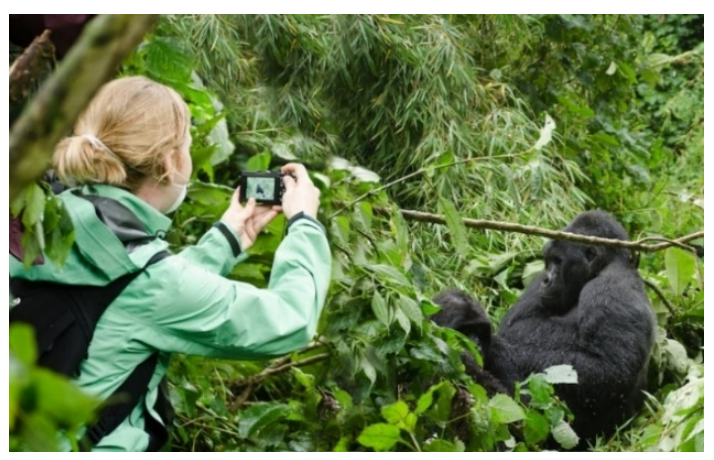

Figure 3: A chimpanzee photographed by a tourist in Taï National Park

Source: Regional Direction of Tourism San-Pedro, November, 2019

This Figure shows a chimpanzee being photographed by a tourist in the Taï National Park located $109 \mathrm{~km}$ from the city of San-Pedro. In addition, it should be remembered that this animal species is protected by UNESCO, as it is of paramount importance for ecological tourism. According to this study, $89 \%$ of tourists made visits to classified forests and Taï National Park to discover certain animal species. After visiting these forests, tourists return to the establishments of the town of San-Pedro for rest.

\subsubsection{A Favorable Climate for Practicing Tourism Almost All Year Round}

One of the primary benefits of the climate is the rainfall regime, which helps attract tourist flows to the town of San-Pedro almost all year round. This rainfall regime is characterized by 3 tourist seasons, including 2 major seasons and one short season (Figure 4). 


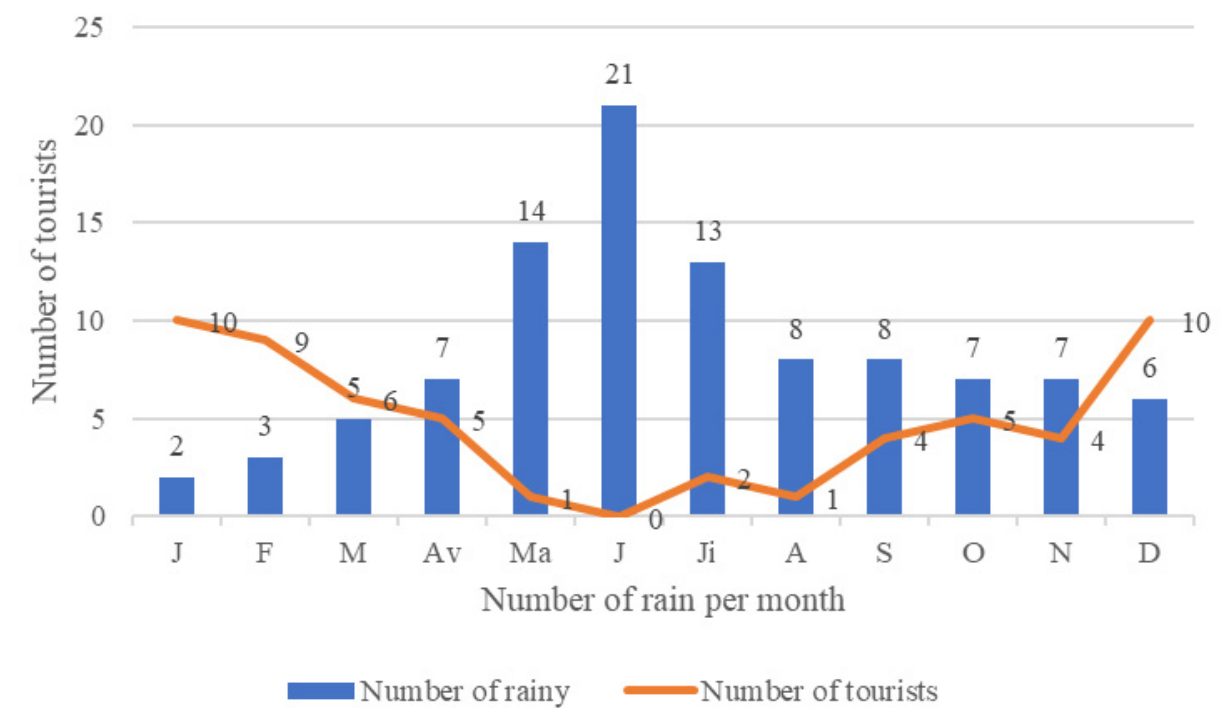

Figure 4. Determination of tourist seasons according to rainfall in San-Pedro in 2020

Source: SODEXAM San-Pedro 2016 and field surveys, March, 2020

Figure 4 above determines the tourist seasons according to rainfall in San-Pedro. It emerges from this graph that $50 \%$ of the surveyed tourists prefer to visit the city of San-Pedro in the months of January to April. This proportion drops sharply from May to July with 5\% of surveyed tourists. From August to December, this proportion increases to $45 \%$ of surveyed tourists. Specifically, it can be deduced that the most popular months for tourists to visit the city of San-Pedro are (January with $33 \%$ of tourists, February 30\%, March $20 \%$ and December $37 \%$ ). Thus, it is found that the months with high rainfall do not offer great travel possibilities for tourists, as $90 \%$ believe that the months with low rainfall are the best time to organize their visits to the city of San-Pedro.

\subsubsection{Human Assets, Contributory Bases to the Tourism Economy}

These assets are, on the one hand, the potential in terms of infrastructure and equipment to attract tourists to the city. On the other hand, the cultural richness of the city to be discovered.

3.1.2.1 An Acceptable Infrastructure and Equipment Potential for the Take-off of Tourist Activity in the City of San-Pedro

Access to the city of San-Pedro is from the outside by two (2) main roads in a state of degradation, which are the Abidjan - Gagnoa, Soubré - San-Pedro axis and the Grand-Bérébi axis - San-Pedro. In addition, within the city there are secondary roads and streets that facilitate the movement of goods and people. In addition, the city has 8 road transport companies, 1 airline and 7 shipping companies which make mobility dynamic. Also, this city has 6 security structures and 19 health structures that reassure tourists to stay there. In addition, for the reception of tourists, the city of San-Pedro is full of several tourist establishments of various standings. In the case of this study, 28 of these establishments were listed, including 13 hotels with 354 rooms, 10 restaurants and 5 seaside resorts with 935 seats (Figure 5). 


\section{Macrothink}

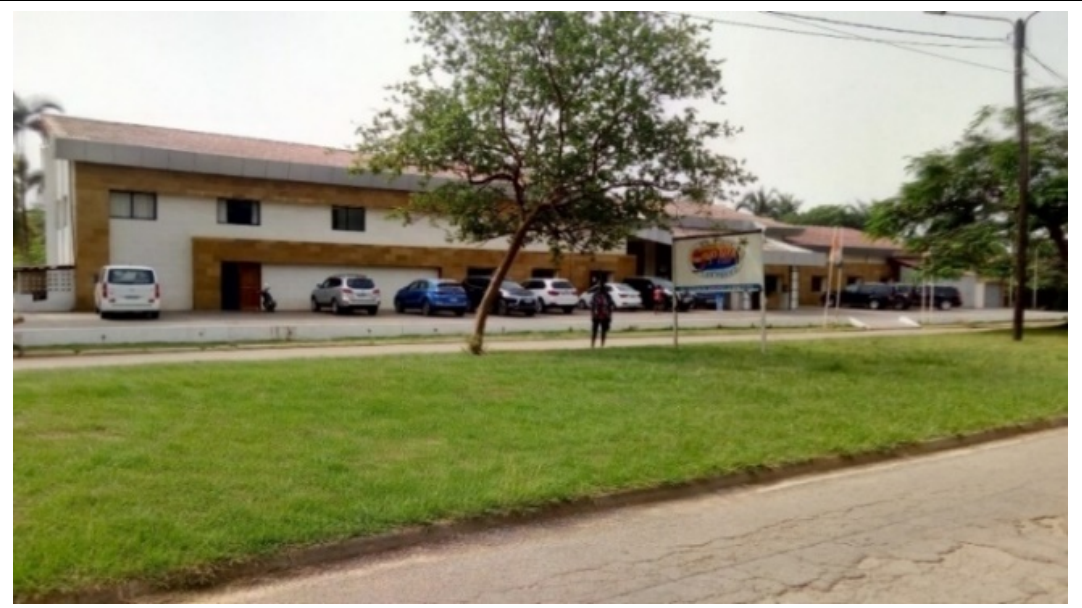

Figure 5. Overview of the "Sophia 'hotel located in the Balmer district of San-Pedro in 2019 Source: Field surveys, November, 2019

Figure 5 shows the Hotel Sophia located in the Balmer district of San-Pedro. This tourist establishment is one of the most luxurious in the city. This works 24 hours a day. Its target customers are tourists with a high standard of living, most of whom are white. According to survey data, its occupancy rate is $40 \%$.

\subsubsection{Cultural Riches to Be Discovered in the City of San-Pedro}

Cultural riches are apprehended through ethno-cultural mixing, annual festivals and the richness of cultural heritage. San-Pedro is inhabited by four (4) large ethnocultural areas which are the Mande, the Voltaïques (Gur), the Akan and the Krou. Thus, the authenticity and creativity of these peoples are expressed through many popular folk dances such as Bollo-super, Sidê or Sida or Petit Lot, generation celebrations, etc. The city authorities organize festivals every year. This was the case of the carnival called "Saint-Pierre" organized from February 21 to February 22, 2019. The aim of this activity is to promote the local culture Kroumen, Winnin, Bakwé and all the other cultures which coexist with these local peoples. (Figure 6).

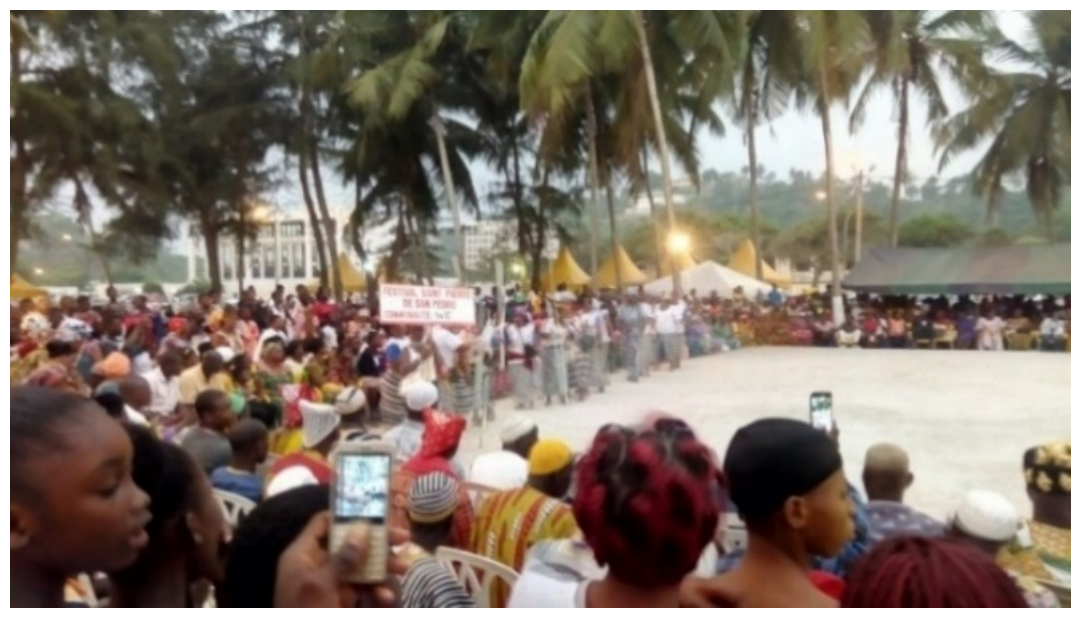

Figure 6. The carnival of Saint Peter of San-Pedro in 2019

Source: field surveys, November, 2019 


\section{Macrothink Institute ${ }^{\mathrm{TM}}$}

Figure 6 shows the carnival of Saint Peter of San Pedro for the year 2020. In this photo, a multitude of people can be seen watching the parade of the town's ethnic group. This mass of people came from various horizons to participate in this festival. These are first and foremost the natives, non-natives and foreigners, most of whom are tourists. $95 \%$ of the surveyed tourists attended this event.

\subsection{The Operationalization of the Tourism Economy in the City of San-Pedro}

This part is devoted to the analysis of the functioning of the actors of the tourism economy and their limits.

\subsubsection{The Functioning of the Actors of the Tourism Economy in the City of San-Pedro}

\subsubsection{Presentation of the System of Actors in the Tourism Economy in San-Pedro}

The legislation of the tourism sector in Côte d'Ivoire is governed by Law No. 2014-139 of March 24, 2014 on the Tourism Code (Ivorian Tourism Code, 2014.p1). This law stipulates that local tourism development policies are implemented by public and private sector actors (Figure 7).

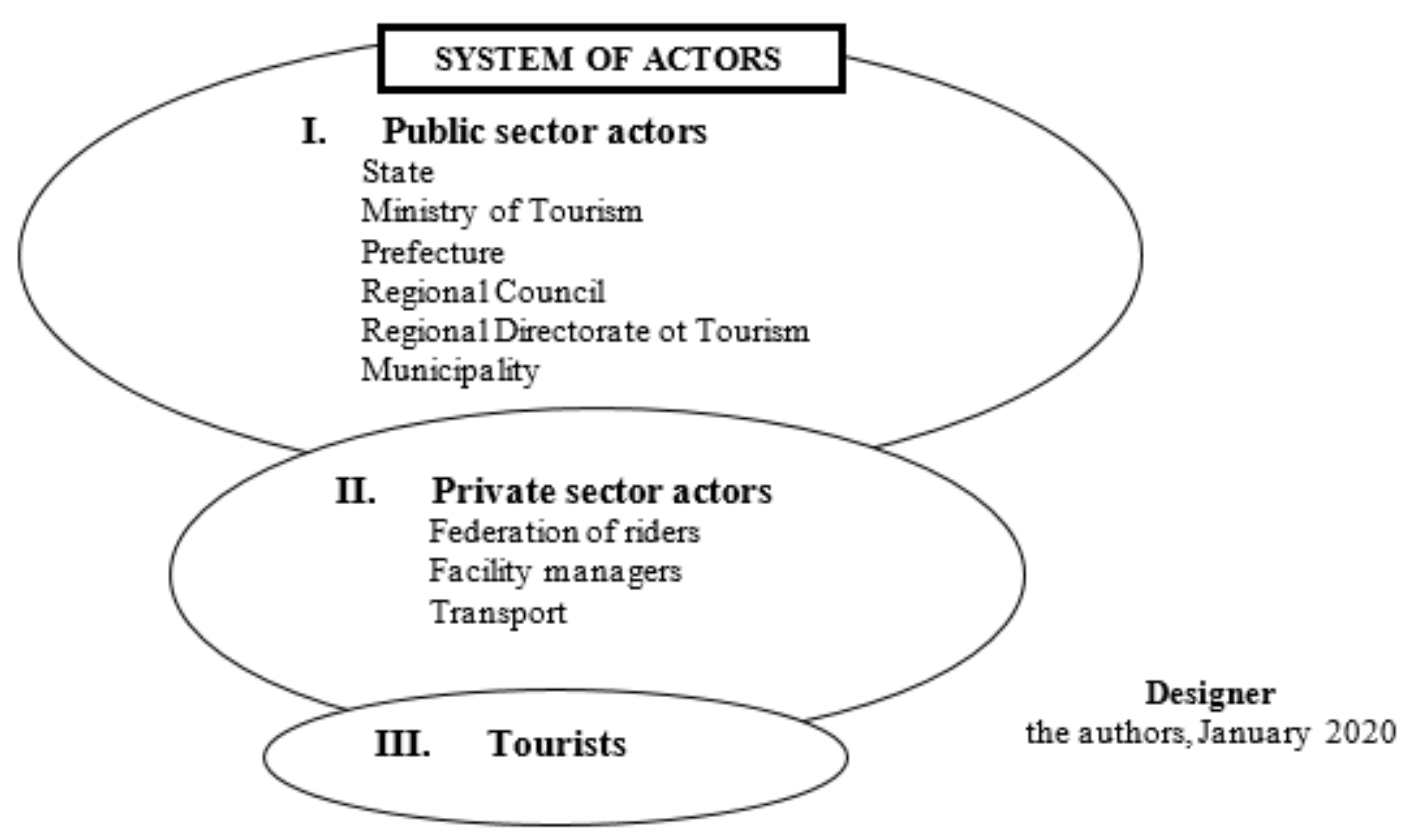

Figure 7. System of actors in the tourism economy of San-Pedro in 2020

\subsubsection{Missions of Actors in the Organization of the Tourism Economy in San-Pedro}

- Institutional actors

Public actors act on two scales. Indeed, the state defines and implements the national tourism policy. To this end, it is responsible for the regularization, planning, programming and control of the execution of public investments as well as the design of tourist structures in the city of San-Pedro.

As concrete actions, the Regional Directorate of Tourism participates every year in the 
Abidjan International Tourism Fair (SITA) to exhibit on the tourism offers of San-Pedro. In 2018 , it organized an activity to raise awareness of the local population on the tourism activity. In 2019, the Regional Directorate produced a film on the region for the promotion of tourism with the help of the San-Pedro regional council. In the same period, the Directorate, in collaboration with the Town Hall and the Regional Council, organized a festival called "Festival de Saint-Pierre".

As for the Regional Council of San-Pedro, its ambition is to make this city the first tourist destination in Côte d'Ivoire and in the sub-region. To do so, the regional council participated in the 6th edition of the Abidjan International Tourism Fair (SITA) in 1019 to provide support to the Regional Directorate of Tourism of the city of San-Pedro. It should be noted that this collaboration between the two structures is common. Each year, the Regional Council makes an inventory of the region's tangible and intangible cultural heritage. This action makes it possible to understand the state of these riches and to enhance them. In terms of cultural animation, the Council organised an artistic holiday at the Degny plage hotel in San-Pedro from 24 July to 25 August 2018. On 21 June 2018 and 2019, it organised a music festival in San-Pedro. In addition, on 16 March 2019, the Francophonie was celebrated in San-Pedro with the aim of making the French language a means of sharing and mutual support between French-speaking countries. Finally, the 25th edition of the national competition called "Festival National Vacances-Culture 2019" was organised from 27 to 31 August 2019 with the theme: the woven loincloth: from tradition to modernity.

-Private actors

In the city of San-Pedro, private actors participate in the development of this sector by making investments and developing human resources. They also promote and develop funding mechanisms. Economic operators are increasingly seeking to improve their business figures by multiplying communication channels. To this end, social networks and ICT are increasingly used. In addition, they are working to raise the quality of service and the standard of their reception facilities.

-Tourists

The tourists' mission is to visit the city of San-Pedro according to their reasons for travel. However, they must comply with the rules set by institutional actors and local economic operators.

\subsubsection{Limits of the Actors in the Organization of the Tourism Economy in San-Pedro}

\subsubsection{At the Level of Public Actors}

In San-Pedro, the shortcomings of the tourism sector can be seen in the actions of institutional actors. The successive municipal authorities to manage the city of San Pedro have not really put tourism at the heart of development and urban planning priorities despite the important assets that it abounds. Thus, the undertaken actions are limited to a few less decisive projects to make tourism a decisive and emerging activity in the city of San Pedro. To this end, $80 \%$ of the economic surveyed operators believe that the municipal authorities take little interest in modernizing gastro-tourist areas and informal seaside resorts. The state's underinvestment in the physical opening up of the city and the lack of investment in public tourist establishments are glaring. 


\subsubsection{At the Level of Private Actors}

In San-Pedro, the lack of training for private actors (economic operators, presidents of umbrella organizations) constitutes a real constraint for the development of tourism activity. Thus, $80 \%$ of these actors confirmed this state of affairs. Also, the means of information and communication on tourism products are insufficient and outdated. Since the city does not have a travel agency, some economic operators of establishments use on-board means to publicize their offers. This is why tourists have provided various means by which they received information on tourist offers in San-Pedro (Figure 8).

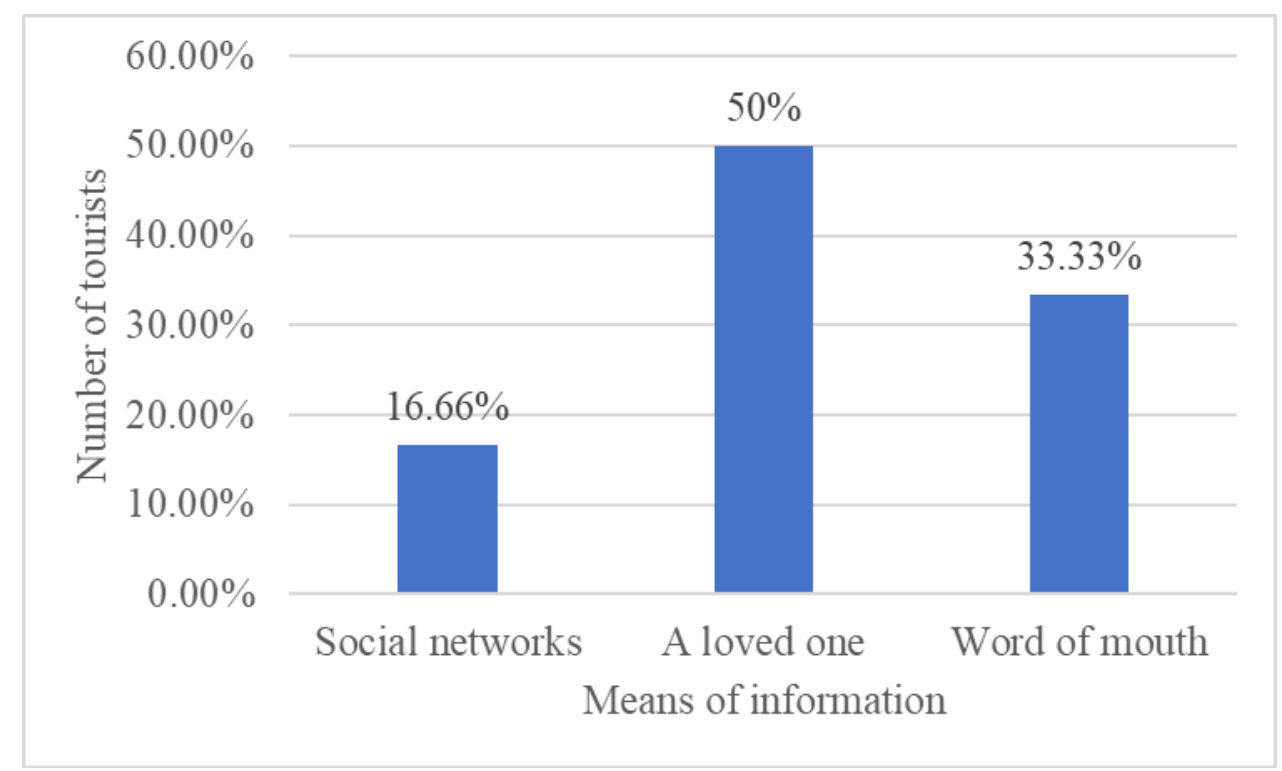

Figure 8. Means of receiving information on tourist offers in San-Pedro according to tourists in 2020

Source: Surveys, March, 2020

Figure 8 above shows the means by which tourists receive information about the tourist offers of the town of San-Pedro. Thus, three (3) means of information are identified. These are: social networks, a relative and word of mouth. Of the sixty (60) tourists surveyed, 30 received information from a relative, or a rate of $50 \%$; 20 tourists received information by word of mouth or $33.33 \%$, and only 10 by social networks or $16.66 \%$. From these observations, it emerges that most tourists receive information on the offers of tourist establishments in San-Pedro by old-fashioned and inappropriate means.

\subsection{Mixed Impact of the Tourism Economy on the Local Development of the City of} San-Pedro and the Prospects for Its Improvement

This part wants to show the impact of the tourism economy on the city of San-Pedro and to formulate proposals to fill the gaps.

\subsubsection{Low Spatial Impact of the Tourism Economy on the City of San-Pedro}

The weakness of the spatial effects of the tourist economy in San Pedro is reflected, on the one hand, by the unequal distribution of tourist establishments and the disparity in the development of the districts surveyed, on the other hand. Out of the 28 tourist establishments 
surveyed, Balmer has 15 establishments or $53 \%$, and the Cité district has 9 establishments or $32 \%$; Sonouko has 2 establishments or $7 \%$, Séwéké 1 establishment or $4 \%$, Sotrèf. 1 establishment or $4 \%$ and the Soleil district has no tourist establishments. This unequal distribution of tourist facilities leads to a disparity in the development of the districts. We can see neighbourhoods with a high level of development as opposed to others with the lowest, due to the unequal distribution of tourist establishments (Figure 9).

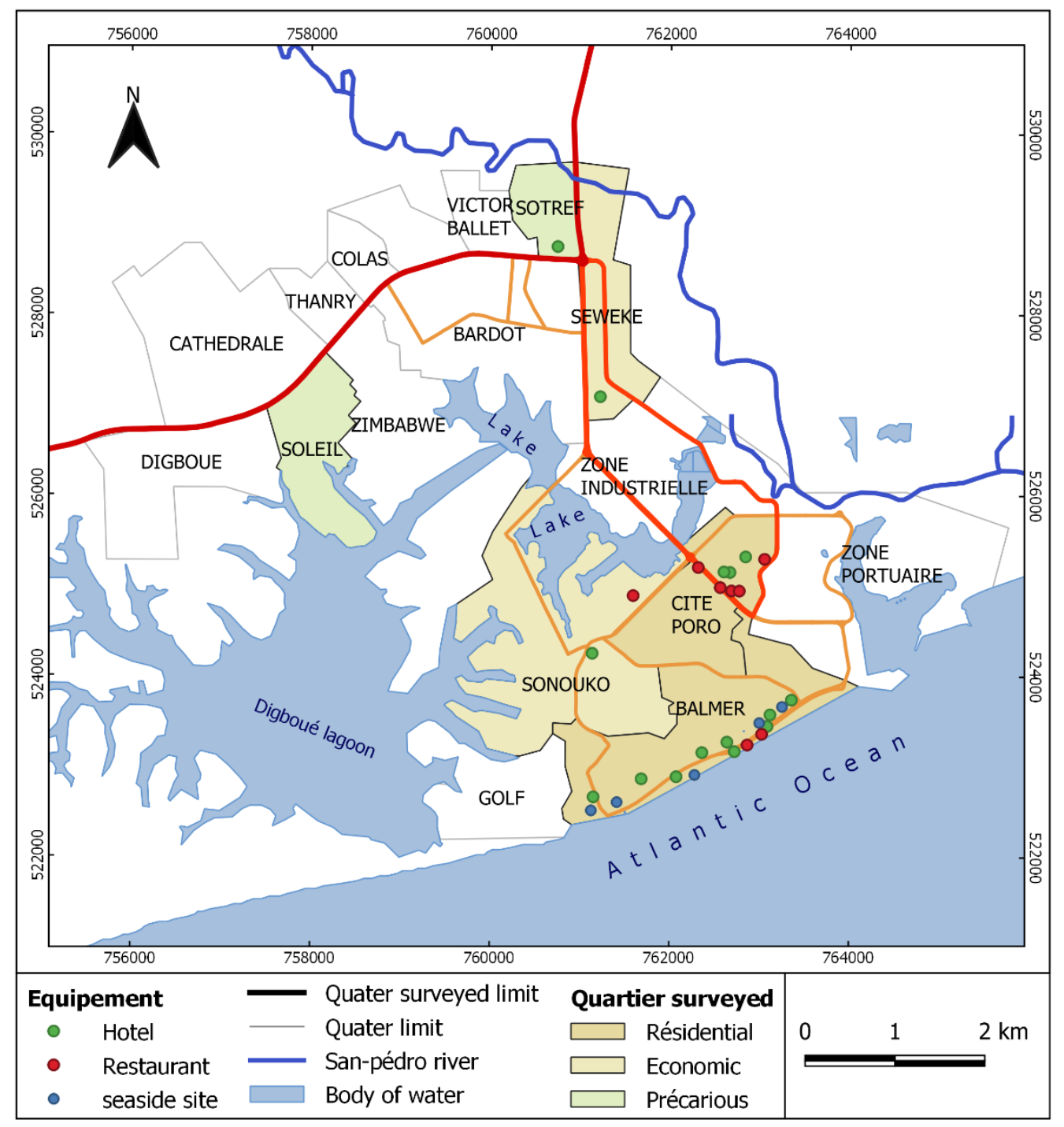

Figure 9. Disparity in development of neighborhoods according to the concentration of tourist establishments in 2020

Source: Town Hall, 2019; SOGEFI, 2019

Realization: the authors, 2020

The areas of the city which have a low number of tourist establishments are lagging behind in development. These are generally the Sonouko, Séwéké, Sotrèf and Soleil districts. They only record $18 \%$ of the surveyed tourist establishments (Figure 3 above). Neighborhoods with a large number of tourist establishments have a medium or high level of development. The 
configuration of the premises also plays a major role here. In this respect, the examples of the Balmer and Cité districts, close to the sea, best summarise our approach. These districts alone account for $82 \%$ of tourist facilities in the city of San-Pedro. Tourist establishments therefore play a dual role in the development of these districts: aesthetic and socioeconomic.

\subsubsection{Social and Economic Impact of Tourism, Barely Perceptible on the City of San-Pedro}

The tourism economy creates direct jobs from tourist accommodation establishments, including receptionists, surface technicians, security guards, restaurateurs, etc. Apart from direct employment, there are induced jobs due to the transversal nature of tourism. These are the jobs such as transport, agriculture, fishing, breeding and crafts as reported by $90 \%$ of economic operators and the two (2) presidents of umbrella federations (Table 2).

Table 2. Opinion of surveyed economic operators on jobs generated by tourism activity in 2020

\begin{tabular}{ll}
\hline Types of jobs & Percentage \\
\hline Qualified & $11 \%$ \\
less qualified & $18 \%$ \\
unqualified & $32 \%$ \\
Precarious & $39 \%$ \\
Total & $\mathbf{1 0 0} \%$ \\
\hline
\end{tabular}

Source: Field surveys, March, 2020.

This Table 2 shows that the tourism economy is viewed as a key area for employment that is valued differently. For $39 \%$ of the respondents, the jobs are precarious and $32 \%$ consider them to be unskilled. On the whole, these results reflect the negligible nature of tourist activity in the economy of San Pedro. On the other hand, for the owners of the tourist sites, the monthly turnover varies from 1,250,000 FCFA to 15,000,000 FCFA. As for the managers of these sites, their monthly remuneration varies from 30,000 FCFA to 250,000 FCFA according to the standing of these places.

In addition, tourist establishments provide benefits to economic operators. The latter, always keen to grow their income, invest them again in various activities (Figure 10). 


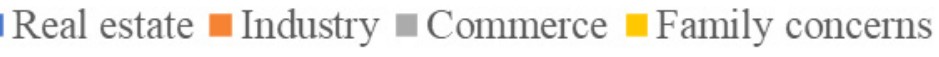

Figure 10. Allocation of the income of the economic operators surveyed in 2020 Source: Field surveys, March, 2020.

Figure 10 above shows the areas of earnings of the economic operators surveyed. It is observed that $46 \%$ use their earnings for family concerns. Operators who invest their earnings in real estate are estimated at $25 \%$. Those who invest in trade represent $18 \%$. Those who invest in industry represent $11 \%$. Thus, economic operators who use their income to meet only domestic needs do so because of their low earnings. According to them, the income from their activity is modest. This does not allow them to invest elsewhere. At the same time, tourists who visit the city of San-Pedro allocate their budget to several activities such as transport, food, accommodation and leisure. To this can be added the expenses made for the purchase of local products (Figure 11).

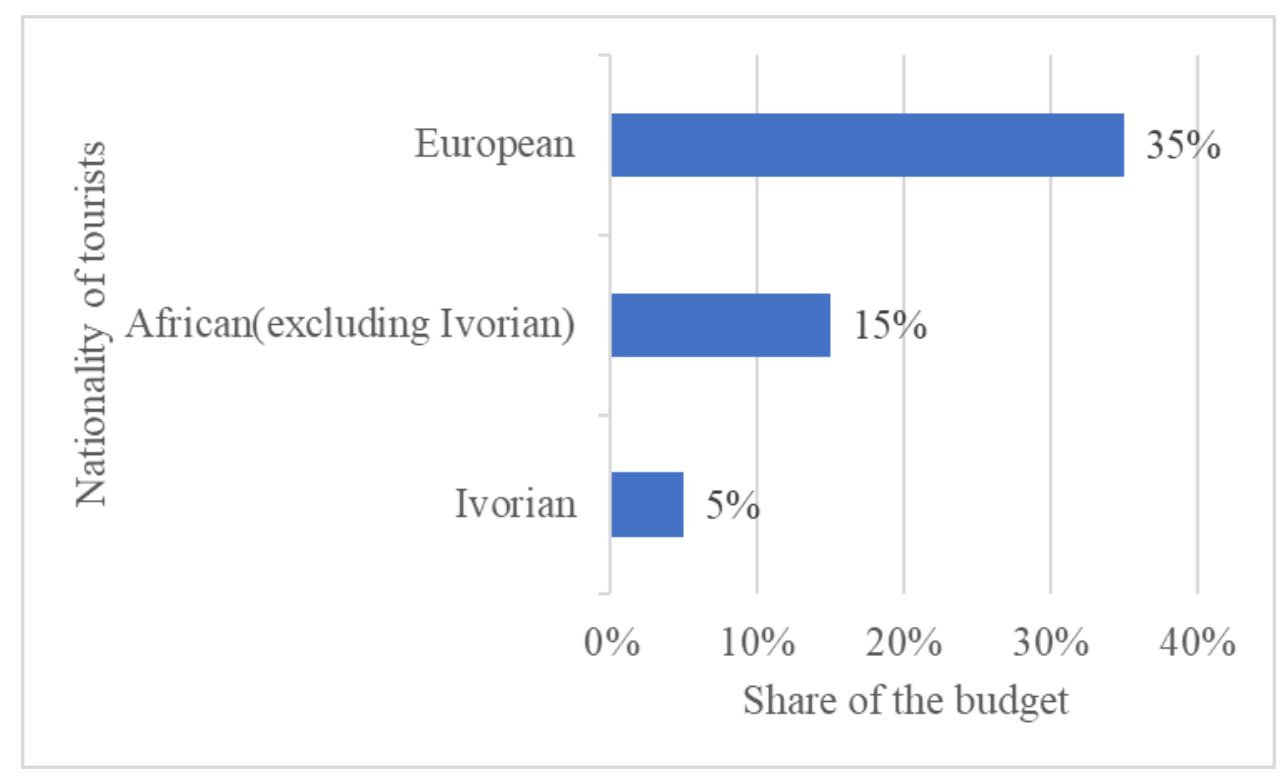

Figure 11. Part of the budget devoted to the purchase of local products by tourists according to nationality in 2020

Source: Field surveys, March, 2020.

The Figure above shows the share of the budget devoted to the purchase of local products 
according to the nationality of the tourists. It shows that tourists who allocate a high share of their budget to the purchase of local products are of European nationality. They allocate 35\% of their budget to these products. They are followed by tourists of African nationality (excluding Ivorian) with $15 \%$. As for tourists of Ivorian nationality, they devote only $5 \%$ of their budget to the purchase of local products. This is justified, on the one hand, by the fact that local products are of little interest to the local tourist and, on the other hand, because of the low budget allocated to tourist activities by the latter.

\subsubsection{Prospects for a competitive Tourism Economy in the City of San-Pedro}

With a view to alleviating the difficulties and improving the development of the tourism economy, three initiatives are to be undertaken in this sector in San-Pedro. First, to develop the attractiveness of San-Pedro by improving road and socio-economic infrastructure. Then, it appears imperative to develop innovation and tourism engineering in San-Pedro. Finally, partnerships between investors in the tourism sector in San-Pedro must be improved.

\section{Discussion}

The results of this study showed that there is undeniable potential for the tourism economy in the department of San-Pedro. Indeed, these natural and human potentialities are the real raw material for tourism. For Lozato-Giotart (1993), space can be considered as the raw material of tourism and, without underestimating other factors, geographical conditions play an essential leading role in the attraction of a tourist place. This is why Claquin (2008) speaks of a tourist area. As a result, a tourist area is an environment capable of stimulating memory (cultural heritage) and the gaze (panoramas or other beauties). And yet, we note that the tourist potential is still in a state of latency or even unexploited because it is mostly unknown in the department of San-Pedro. As for Hauhouot (2008), he argues that natural potential alone could not be able to develop tourism, but cultural potential should be added. Gorgui (1983) and Aphing-kouassi (2001) complement this by pointing out that no tourist activity is possible in a region where the populations are xenophobic. The study also shows that the town of San Pedro has a diverse range of tourist facilities. This is made up of hotel accommodation $(32.5 \%)$, restaurants $(25 \%)$, socio-cultural heritage $(30 \%)$ and beaches $(12.5 \%)$. In spite of the diversity of the tourist offer, the tourist economy encounters difficulties on the organizational level and on the level of investments, which limits the effects on the development of the city of San Pedro. To this, we must add that the growth of this activity suffers from a lack of culture on the part of the population and a lack of professionalism in the field, thus hindering the collective will to mobilize local resources in order to build a homogeneous territory or even a global development project (Merlin et Choay, 2015). These results are similar to those of Meirama (2016). This author claims that in the regions of Cameroon, people find it difficult to integrate the tourism economy into their daily lives. The author also points out that the eastern region of Cameroon faces a lack of human resources responsible for organizing the tourism economy. As for Bouaouinate (2016), she attests that the lack of professionalism of certain tourism actors, who only have a short-term, mercantile vision, contributes to creating relations of conflict and tension between them. To some extent, tourist facilities are marginalized in spatial planning policies (Derruau, 2012). This sector is often confronted with insufficient investment in hotel and road infrastructure (Dabitora, 2016). Aspects that Yapi-Diahou and Simeu-Kamdem (2018) do not 
fail to highlight by emphasizing the "finishing touches" or better finishing of hotel infrastructures in the cities of sub-Saharan Africa. For these authors, hotel establishments present in their finishes sometimes disconcerting shortcomings and insufficiencies even if they present the image of luxury hotels. Thus, Meirama (2016) concludes that the lack of investment and the lack of supervision make it possible to better understand the many basic difficulties. This is the lack of a promotion and professionalism strategy in the reception establishments, as well as the lack of synergy between the various players in the sector. Moreover, the tourism economy does not significantly impact the spatial and socioeconomic development of the city of San-Pedro. However, it is found to provide in terms of direct and indirect job creation. However, the number of jobs is relatively low and poorly paid in view of the many potentialities. These results are different from those of M. Diombera (2013) on the small Senegalese coast.

\section{Conclusion}

This study has endeavoured to assess the impact of the tourism economy on local development in the city of San Pedro. Indeed, this city has undeniable tourist potential, both natural and human. However, the tourism economy still contributes little to the development of the locality due to organizational dysfunctions and low investment. These constraints attenuate the spatial and socio-economic impact of this activity on the town. Thus, all the actors of the sector are called upon to work to develop the attractiveness of San-Pedro, tourism engineering and the improvement of partnerships between investors. It is at this collective price that the tourist economy will be able to satisfy its quest for local development.

\section{References}

Aphing-Kouassi, N. G. (2001). Coastal tourism in the Ivorian southwest, 3rd cycle doctoral thesis in Geography, Cocody-Abidjan University, p. 340.

Ashley, C. (2002). Methodology for Pro-Poor tourism case studies, PPT working paper No.10, Overseas Development Institute.

Bencheikh, A., Gariépy M., Pouillaouec-Gonidec P., Baillard, V., \& Hardy, H. (1999). The structuring effect of tourism on the urban territory: the cases of Marrakech and Agadir. The urbanization of countries on the way development, Economica.

Bouaouinate, A. (2016). The development of tourism in oasis areas in Morocco from mass tourism to alternative tourism. Synthesis Report of Scientific and Educational Work. Geography. Hassan II University Casablanca; Mohammedia Faculty of Letters and Human Sciences.

Claquin, B. (2008). Cultural approach of the communities of traditional fishermen and tourism development of the islands of Mozambique. Doctoral thesis in Geography. University of Reunion, 275 pohammedia.

Degui, J-L, Kouadio, K. A., Essan, K. V., \& Aloko- N'guessan, J. (2019). Diagnosis of the tourist offer in the south-eastern region of Côte d'Ivoire: case of the departments of Grand-Bassam and from Adiaké. Revue Ivoirienne de Géographie des Savanes, June 6, pp. 283-304.

Derruau, M. (2012). Human Geography, Paris, Armand Colin, p. 447. 
Diombera M. (2013). Tourism and local development: towards a redefinition of relations at the level of the Senegalese Petite-Côte? https://doi.org/10.4000/etudescaribeennes.6736

Gagui, M. S. (2011). Diagnostic study of the tourist sector in the town of GRAN-BASSAM, DECEP- INJS thesis, Abidjan.

Gorgui, C. (1983). The development of the Small Senegalese Coast, 3rd cycle doctoral thesis in Geography, University of Bordeaux.

Hauhouot, A. A. (2008). Nature, culture, tourisme en Côte d'Ivoire, Essay on the trilogy of a failed development bet, ESSAI Collection, University Publishing of Côte d'Ivoire, University of Cocody-Abidjan.

Koumantiga, D., \& Akpagana, K. (2012). Ecotourism potentialities in the prefecture of Doufelgou (Togo, West Africa), Études caribéennes.

Lozato-Giotart, J-P. (1993). Geography of tourism, Masson. p. 237.

Meirama G. M. (2016). Heritage resources and tourism prospects in Eastern Cameroon: current potentialities and limits. Études caribéennes.

Merlin, P., \& Choay, F. (2015). Dictionary of town planning and development, Paris, Quadrige.

Perrain, D. (2018). Tourism in small island economies: analysis of the fundamentals of tourism specialisation as a sustainable source of growth', $\mathrm{PhD}$ thesis in Economics and Finance. University of Reunion.

Yapi-Diahou, A., \& Simeu-Kamdem, M. (2018). The finishing touches or the weak link in the luxury hotel industry in sub-Saharan Africa, under the direction of Michel SIMEU-KAMDEM and Touna MAMA, City policies in question (In search of better urban governance in sub-Saharan Africa), Cameroon, L'Harmattan, pp. 111-121.

\section{Copyright Disclaimer}

Copyright for this article is retained by the author(s), with first publication rights granted to the journal.

This is an open-access article distributed under the terms and conditions of the Creative Commons Attribution license (http://creativecommons.org/licenses/by/4.0/). 